\title{
A Navigation Device for Steering Vehicles on the Polar Ice-Cap
}

\author{
from H. P. Black \\ (Officer-in-Charge, Australian National Antarctic Research Expedition, Wilkes Station, \\ Antarctica, 1960)
}

1. Introduction. Precise navigation upon the ice-cap depends largely upon the accurate steering of a chosen course. This operation can be rendered difficult by three major problems commonly faced by Arctic and Antarctic expeditions. First, the absence of topographic features as points of reference; secondly, the loss of precision of the magnetic compass inside a moving vehicle and in areas adjacent to the Magnetic Pole; thirdly, the dependence of the astro-compass and similar instruments upon an unobscured Sun.

A simple method by which these difficulties are overcome was tested and found satisfactory during an inland traverse from Wilkes Station in NovemberDecember 1960 into an area not previously explored by land. The principle of this method is the use of a periscope-like arrangement of mirrors combined with a suitable sighting system to enable the driver to use his track astern to steer a straight course ahead.

2. Construction. The original device was installed upon a vehicle (a 'Weasel'), already fitted with an astro-compass and a magnetic compass in order to function as the navigation vehicle of the train. The rear vision mirror taken from a 'Traxcavator' was used as the main 'Track mirror'. It was pivoted at its centre point through the shorter axis. The mirror was mounted on a frame of two half-inch steel pipes bolted on to the vertical wall of the well between the windscreen and the forward hatch of the Weasel. This frame was secured by means of two brackets fastened to the front panel above the windscreen and braced with steel wires for rigidity.

A small 'driving mirror' was pivoted on a bracket near the base of the uprights, directly in front of the driver, and square with the long axis of the vehicle. The mirror mountings were made adjustable in order to provide both vertical displacement and inclination fore and aft. All mountings were made relative to a straight line drawn along the top surface of the roof, passing through the centre of the driving seat and parallel to the longitudinal axis of the vehicle. At the rear of this line was bolted a vertical sighting rod; a thin sighting line was laid centrally through the long axis of the driving mirror.

3. Operatron. (a) Course laying. The desired azimuth was transferred to a surface course, usually by the use of an astro-compass, by lining up flagged stakes over a distance of several hundred metres. The navigator then drove carefully from flag to flag in order to produce as straight a line as possible; the course became an extension of that line. On some occasions a second vehicle, despatched to a position 500 metres or more in rear along the track, was precisely positioned on a back bearing from the navigation vehicle by radio telephony or visual signals, thus providing the necessary reference by which the navigation vehicle proceded. Course marker stakes set out at the end of the day's run facilitated starting procedure next day, particularly when marginal weather conditions precluded the use of astro sightings. 
(b) Driving on course. The driver maintained correct heading by means of his straight-line track projected forward into the driving mirror and lined up with the image of the sighting rod mounted on the rear of the vehicle's roof and the reference mark on the driving mirror itself. Simultaneous attention to the mirror image and to the rough surface of the plateau was accomplished quite

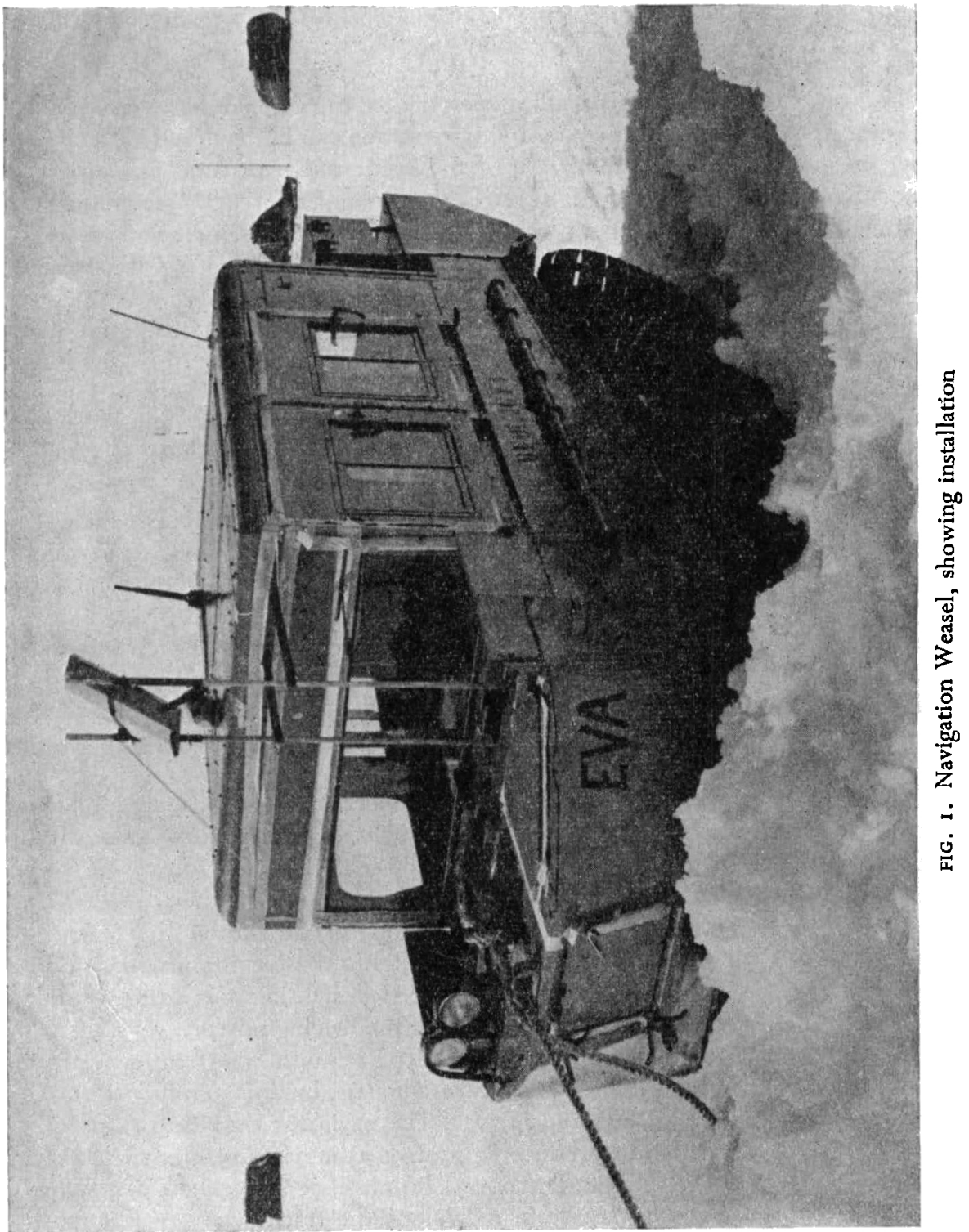

successfully after a little practice. It was found to be important for the driver to be on his guard for surface obstructions, particularly whilst learning the technique; in dangerous areas slow speed was called for or, more desirably, a person acting as lookout. 
Driving was facilitated when the navigation vehicle's steering system was adjusted to provide straight-line travel over level terrain. Oscillation of the mirror image caused by rolling and pitching of the vehicle was soon accommodated by the human reflexes. The inverted image presented in the driving mirror did not provide any visual difficulty. Contrary to expectations, no additional strain appeared to be sustained by the eyes of the driver.

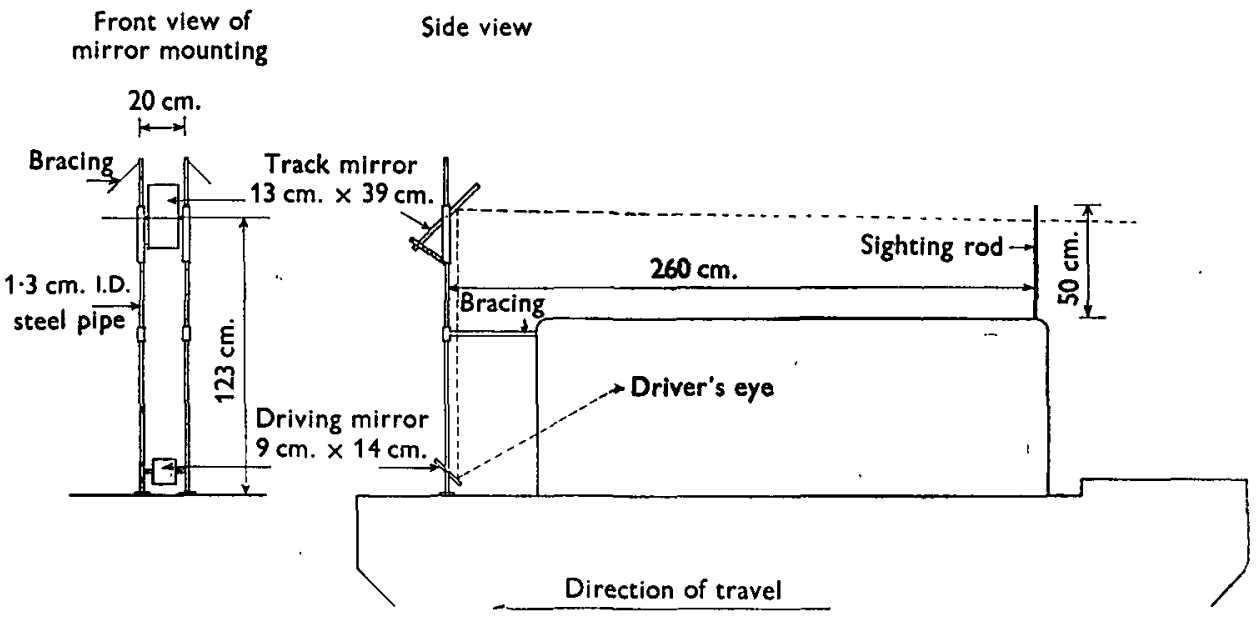

FIG. 2. Mounting of mirrors

A second vehicle faithfully following the tracks of the navigation vehicle was found to provide a superior reference mark to the track itself, being much easier to 'sight' in the driving mirror and allowing accurate registration under deteriorating weather conditions ranging to 'whiteout'. Increased accuracy was obtained when the second vehicle maintained the greatest possible separation compatible with remaining visible over the intervening terrain or through an obscured atmosphere.

The negotiation of natural obstacles naturally reduced performance. In practice it was found possible to compensate for such diversion by lining up the 'true' track on the far side of the obstacle with the trailing vehicle. By this means areas of very rough sastrugi with an amplitude of one metre were negotiated without significant diversion from the planned course over the whole run. The line of the track and the true heading were regained by the leading vehicle as soon as possible after flanking the obstacle. The navigating driver experienced no difficulty in discerning the altered silhouette when the second vehicle deviated; he then waited for the vehicle to straighten on course before once more registering upon it.

A certain degree of teamwork was required in the operation. The rear vehicle adjusted the separating distance to the terrain. The occurrence of undulations or other surface features of magnitude required the trailing driver to reduce to a minimum the period in which his vehicle was out of sight of the leader. In the meantime the navigator was forced to register upon the less visible line of tracks.

(c) Course adjusting. Periodic checks of track were carried out in order to minimize course error, the interval being dictated by the degree of accuracy 
required. The driver aligned the vehicle precisely along the line of his track as the vehicle came to rest. Reference to the astro-compass or magnetic compass (at rest) then demonstrated any deviation from the planned course. A compensating slight alteration of heading over a calculated distance corrected any error.

4. Results. The accuracy of the new navigation device was compared to that of traditional methods of steering course relative to terrestrial features such as dunes or sastrugi, and to transient features such as cloud formations, all of which tended to introduce errors of considerable magnitude. Another wellknown method whereby binoculars were used to line up stakes in rear as a means of maintaining course proved impracticable over long distances. These stakes could not be sighted satisfactorily whilst the vehicle was in motion and, because of exaggerated perspective, aberrations of course were extremely difficult to assess, necessitating frequent re-correction. The technique proved to be timeconsuming and fuel-wasting and, by increasing the incidence of 'stops and starts', imposed undesirable strain upon loaded vehicle trains.

On the other hand, with the new navigation device and reasonable driving care exercised under average conditions of surface and visibility, each leg of a traverse was maintained to $\pm 2^{\circ}$, and often within $0: 5$. It was found in practice that errors were distributed randomly to port and starboard, the net error being small. Stages through areas of rough sastrugi were maintained within $3^{\circ}$. When compensating action followed frequent checks of heading, the overall track lay within $0 \% 5$ port and starboard of the course steered.

Further confirmation of the efficacy of the device has just come to hand. A letter received by the author from Antarctica and written by Robert Thomson, Officer-in-Charge of the A.N.A.R.E. Expedition at Wilkes in 1962, refers to his three-month inland traverse to the Russian base Vostok, $1420 \mathrm{~km}$. distant (a round trip of $2850 \mathrm{~km}$. and the longest journey carried out by Australians in the Antarctic). He states that 'the device worked excellently and contributed greatly to the success of the navigation'.

Captain Neville Smethurst, Officer-in-Charge at Wilkes during 196I, reported in similar terms concerning the use of the device during his $560 \mathrm{~km}$. inland traverse.

5. Conclusion. In areas like the Antarctic or Greenland ice-caps where a lack of topographic features inhibits accurate steering of course, where the proximity of the Earth's Magnetic Pole renders the magnetic compass unreliable (particularly for vehicle use), and in marginal weather which prevents travel based upon celestial observations, a navigating vehicle's own track offers a valuable means of maintaining an accurate dead reckoning course. This method was successfully employed in Wilkes Land in 1960; although other expeditions may have utilized the same principle no published reference to the method appears to exist. The simple pioneer device here described could no doubt be improved by the use of more sophisticated optical equipment. It can be fitted to any kind of vehicle and might also prove useful over deserts or wide, featureless plains. 